\title{
Gastrointestinal Complications Following Cardiac Surgery.
}

\author{
Alfred Ibrahimi ${ }^{1}$, Saimir Kuci ${ }^{1}$, Ervin Bejko ${ }^{1}$, Stavri Llazo ${ }^{1}$, Jonela Burimi ${ }^{1}$, Esmerilda \\ Bulku$^{1}$
}

\begin{abstract}
Aim: Gastrointestinal complications (GIC) following open heart surgery usually are rare but with high morbidity and mortality. The aim of this study was to see the outcome of these patients after complication, compared with a similar study found in literature. Identifying risk factors preoperatively and postoperatively in our patient's series, for GIC.

Materials and methods: Between January 2012 and December 2017 from 1990 operated cardiac patient 34 of them developed GIC, presenting gastro duodenal bleeding due to active ulcer, liver failure, pancreatitis, cholecystitis, or intestinal ischemia. We performed a retrospective analysis.

Results: From all consecutive patient only $1.7 \%$ developed GIC. Mortality rate was $55.8 \%$, especially $100 \%$ mortality in intestinal ischemia patient. Regarding risk factors, those were the same found in other similar study (age, atherosclerosis disease, by pass time, postoperative ARF, Low cardiac output syndrome.)

Conclusion: GIC after cardiac surgery are rare but when it happens the mortality is very high not even of late diagnosis. In ages patients, diabetes, long by pass time, long hypoperfusion state. It is recommended to be alert for GIC for detection in early phase, and for reducing as much as possible morbidity and mortality.
\end{abstract}

Keywords: cardiac surgery, gastroduodenal ulcer, non-occlusive intestinal ischemia. cholecystitis.

*Corresponding author: Alfred Ibrahimi

$\equiv$ E-mail: alfredibrahimi@hotmail.com

1Department of Anesthesia and Intensive Care. University Hospital Centre "Mother Teresa", Tirana, Albania. 


\section{Full Text}

\section{Introduction}

Gastro-intestinal complications (GIC) such as: gastroduodenal ulcer, hepatopancreatitis, colecistits, paralitic ileus, non-occlusive intestinal ischemia are one of the serious extracardiac events following open heart surgery. These complications are increasing as population ages, frequently reported in high risk patients. The incidence varies from $0.2-14 \%$ to $5.5 \%$ [1-4]. The morbidity and mortality is very high in cases when complication occur; it ranges from $13.9 \%$ to $100 \%$ [5-7]. Cardiac surgery is a risk factor for intra-abdominal complication. [8].The main reason is the visceral hypoperfusion during intra and postoperative period, also systemic inflammatory syndrome (SIRS) triggered by extracorporeal circulation [9]. It, s difficult to diagnose the complication because most of the patient are sometimes fully sedated in ICU, or under postoperative analgesia. Sometimes diagnosis is confirmed very late. GICs may compromise the life of the patient and increase the hospital costs and prolonged ICU stay. The purpose of this study was to investigate predictors of development of GICs in order to protect against these complications.

\section{Methods}

We retrospectively analyzed 1990 consecutive patients, during January 2012 and December 2017 timeframe, who underwent open heart surgery with cardio- pulmonary by pass (CPB). Off pump and pediatric congenital surgery were excluded from this study. Operation procedure consisted in isolated valve surgery, coronary by-pass grafting $(\mathrm{CABG})$, combined $\mathrm{CABG}$ valve, combined CABG with carotid endatherectomy, type A aortic dissection. Emergency operations were also included in the study. Whole information regarding patient illnesses, history and other comorbities like: diabetes (DM), peripheral and vascular (PVD), chronic renal damage (CRD), chronic hepatitis $(\mathrm{CH})$, chronic pulmonary obstructive disease (COPD), life style (smoking, alcool) were collected to determine risk factors. Preoperatively, all patients were premedicated with Midazolam 7,5 mg. In operative room anesthesia was inducted with Fentanyl $5 \mu \mathrm{g} / \mathrm{kg}$ and Propofol $3 \mathrm{mg} / \mathrm{kg}$ and pancuronium 0.1 $\mathrm{mg} / \mathrm{kg}$ (depending in a left ventricular function). Anesthesia was maintained with fentanyl total dose $30 \mu \mathrm{g} / \mathrm{kg}$, propofol $10 \mathrm{mg} / \mathrm{kg}$ and sevoflurane $1-2 \%$. Tranexamic acid 1 gr was used as antifibrinolytic drug, after cannulation of three lumen 7,5 FR central venous catheter. For prophylaxis cefuroxime $1,5 \mathrm{~g}$ was used as antibiotic. Pantoprazole $40 \mathrm{mg}$ was used as proton pump inhibitor (PPI) from the first to fourth postoperative and day H2-receptor antagonists in successive days. All the interventions were performed through median sternotomy and $\mathrm{CPB}$ with fiber membrane oxygenation. Pulsatile blood flow $2.5 \mathrm{~L} / \mathrm{min}$ was used and normothermia was maintained during operation. Tepid cardioplegia was used (first dose in $4^{\circ} \mathrm{C}$ St Thomas Solution, and after $20 \mathrm{~min}$ blood potassium cardioplegia in normal temperature). Weaning from $\mathrm{CPB}$ in case of low cardiac output, inotropic drugs were used and in case of excessive inotropic support and hemodynamic instability intra- aortic ballon pump (IABP) was inserted. 
Statistical analysis was performed using SPSS (Statistical Package for Social Sciences), Results are given as mean $\square$ SD. To evaluate independent risk factors for GICs, significant multivariate risk factors were examined using stepwise logistic regression analysis. P-values of less than 0.05 were considered statistically significant.

\section{Results}

The total number of patient who underwent open heart surgery with CPB was 1990. All of them were divided in 1225 (61.5\%) only CABG patients, $732(37 \%)$ valve patients, $34(1.7 \%)$ aortic dissection patients, and $85(4,2 \%)$ combined operation patients. Seriously abdominal complications were seen only in 34 $(1,7 \%)$. Mortality was $55,8 \%$ in patients with gastrointestinal complications. Whole characteristics of comorbidities and surgical procedures were collected and seated in table 1 and 2.

\begin{tabular}{|c|c|c|c|}
\hline Variables & Control (1990 cases) & GICs (34 cases) & $\mathrm{p}$ \\
\hline \multicolumn{4}{|l|}{ Clinical characteristics } \\
\hline Age (y) & $54.3 \pm 9.4$ & $70.0 \pm 8.9$ & 0.01 \\
\hline Age 63 & 660 & & 0.02 \\
\hline Sex (male/female) & $1512 / 388$ & $30 / 4$ & \\
\hline \multicolumn{4}{|l|}{ Cardiac data } \\
\hline Coronary surgery & $1176(59.1 \%)$ & $21(61.7 \%)$ & 0.051 \\
\hline Valve surgery & $695(34.9 \%)$ & $10(29.4 \%)$ & 0.42 \\
\hline Aortic dissection & $34(1.7 \%)$ & $3(9 \%)$ & 0.34 \\
\hline Combined patient & $85(4.2 \%)$ & 1 & \\
\hline Emergent operation & $89(4.4 \%)$ & 3 & 0.075 \\
\hline $\operatorname{LV} \mathrm{EF}(\%)$ & $43.5 \pm 16.2$ & $43.4 \pm 10.3$ & 0.01 \\
\hline $\mathrm{LV}$ EF $\leq 40$ & 108 & 11 & 0.01 \\
\hline \multicolumn{4}{|l|}{ Coronary risk factors } \\
\hline Hypertension & $375(26,1 \%)$ & $7(20,6 \%)$ & 0.32 \\
\hline Diabetis mellitus & $366(18.3 \%)$ & $15(44 \%)$ & 0.002 \\
\hline Cerebrovascular disease & 45 & 8 & 0.005 \\
\hline Peripheral arterial disease & $135(6.7 \%)$ & $9(26 \%)$ & 0.002 \\
\hline COPD & $122(6 \%)$ & $2(5,8 \%)$ & 0.50 \\
\hline Smoking & $580(29.14 \%)$ & $9(26,4)$ & 0.28 \\
\hline CRF & $104(5.2 \%)$ & $10(29.4 \%)$ & 0.002 \\
\hline
\end{tabular}

Table 1: Patients clinical characteristics and comorbidities. 


\begin{tabular}{lccc}
\hline & Control (1990 cases) & GICs (34 cases) & P \\
\hline Emergency surgery & $103(5.2 \%)$ & $7(20 \%)$ & 0.006 \\
ECC time (min) & $92.8 \pm 48.3$ & $125 \pm 52$ & 0.001 \\
Aortic cross clamp time (min) & $63.4 \pm 37.8$ & $79.48 \pm 56.5$ & 0.07 \\
Time of surgery (min) & $215 \pm 72$ & $255.5 \pm 76.8$ & 0.007 \\
Major complication & & & \\
Reexploration for bleeding & $88(4.4 \%)$ & $2(5,8 \%)$ & 0,15 \\
Blood transfusion (pack) & $640(32.1 \%)$ & $(94.1 \%)$ & $<0.0001$ \\
Low card syndrom & $260(13 \%)$ & $18(52.9 \%)$ & 0.001 \\
$\quad$ IABP use & 27 & 2 & 0.4 \\
$\quad$ Hemofiltration & $48(2.4 \%)$ & $4(11.7 \%)$ & 0.016 \\
$\quad$ Postoperative stay (day) & $25.1 \pm 16.7$ & $44.9 \pm 17.9$ & 0.005 \\
$\quad$ Lactates & $1.15 \pm 0.1$ & $5.34 \pm 3.4$ & $<0.002$ \\
\hline
\end{tabular}

Table 2. Operative and postoperative data.

Regarding the patients who developed GIC all the data are presented in table 3. Patients with gastric duodenal ulcer were diagnosed after anemia and melena were the first signs. After fibro-gastroscopy was done, no active bleeding was noted, except in one patient with massive bleeding that ended in exitus after a few days. Other complications are discussed below.

\begin{tabular}{ccc}
\hline Symptoms & Time of diagnosis & Deaths \\
\hline Gastric duodenal ulcer 4 & $10 \pm 6.5$ day & 1 \\
\hline Cholecystitis 3 & $10 \pm 4.5$ day & No \\
\hline Intestinal ischemia 13 & $8 \pm 4.3$ days & All dead \\
\hline Liver failure 8 & $3 \pm 1$ days & 4 \\
\hline Appendicitis 2 & $8 \pm 2$ days & All alive 1 \\
\hline Acute pancreatitis $\mathbf{2}$ & $7 \pm 3$ days & 1 \\
\hline Perforation 1 & 15 days & 0 \\
\hline Sigma perforation $\mathbf{1}$ & 14 days & 0 \\
\hline
\end{tabular}

Table 3. Diagnosis, and outcomes in 34 patients who developed abdominal complication. 


\section{Discussion}

Gastro-intestinal complications such as: gastro-duodenal ulcer, hepato-pancreatitis, intestinal ischemia, are relatively rare after cardiac surgery with an incidence ranging from $0.2 \%$ to $5.5 \%$ [3], but mortality is very high when they occur [(range 13\% - 87\%) [5]. The incidence in our study was $1.7 \%$ and mortality in gastrointestinal group was 55.8\%.

\section{Witch are the major factors influencing in GICs?}

All the factors who can lead to splanchnic hypoperfusion and later in ischemia are the factors for GICs. The splanchnic circulation plays an important defensive role in hypovolemia and during low output syndrome. When vasoconstriction occur due to hypovolemia or low cardiac output, splanchnic vessels may contribute in $15 \%$ of blood volume increase. The same events occur during CPB [10-12]. Splanchnic ischemia plays a key role in the initiation and perpetuation of the systemic inflammatory response syndrome (SIRS) that often follows cardiac surgery under $\mathrm{CPB}$. Two controversy opinions exist regarding the principal role of $\mathrm{CPB}$ in initiation of SIRS and adverse of GI event. Emmiler et al [13] in a retrospective study of 2,625 patients, compared patients operated with the heart- lung machine with patients who were operated off pump. The intestinal ischemia incidence was $0.4 \%$ for the first group versus $0.2 \%$ for the latter. Similarly, mortality rate for the first group reached $0.2 \%$, while the off pump group presented no deaths. But, Chroome et al. [14] did not find any differences of total GIC between the off- pump and on-pump group. The same results are reported by Poirier [15].

The most common GI Complication following open heart surgery is hemorrhage from upper GI tract. [16,17]. The two most common aetiologies are gastro-duodenal ulcer and erosive gastritis[18]. In our recent study the incidence of bleeding was $11.7 \%$ compared with $31 \%$ in other studies. Interestingly, in numerous published papers, we noted that GIC especially, hemorrhagic episodes did not decline through the years despite constant improvement in medical management. In our case is different.

The most devastating complication was severe intestinal ischemia which later progresses in necrosis. It is attributed to hypoperfusion during extracorporeal circulation or perioperative hemorrhage, as well as to thromboembolic episodes occasionally influenced by heparin-induced thrombocytopenia. It is possible that presence of coronary artery disease is associated with vasculopathy in mesenteric bed, thus potentially predisposing a patient to more ischemia in peri-operative period. The pathophysiological mechanism of intestinal ischemia is not yet understood. Acute mesenteric ischemia after cardiac procedure is due to non-occlusive mesenteric ischemia (NOMI), rather than embolic one. [19]. In our series, the incidence was 0.05 in total population but $38 \%$ in gastrointestinal group. The mortality was $100 \%$ because of delayed diagnosis. Schoots [20] reported an overall mortality rate of about $95 \%$ for non-surgically 
treated patients. The diagnosis was made with contrast CT and confirmed after laparotomy.

Hepatic failure is associated with high mortality about $74 \%$ but is very rare $(0.1$ $1.1 \%$ ) [21]. Characteristics of hepatic failure are 10 to 20 times elevated hepatic enzyme and high bilirubinemia due to liver ischemia. [22]. There is connection between low cardiac output syndrome, high elevated lactatemia and multi organ failure.

Acute pancreatitis during perioperative period is rare and it ranges from subclinic to hemorrhagic form. The pathogenesis is unclear. Out of two patients, one of them ended in exitus.

Acute cholecystitis is another abdominal complication following cardiac surgery. Usually the cholecystis are acalculous and pathophysiology is still unclear. Visceral hypoperfusion, endotoxemia, and overproduction of inflammatory mediators have been suggested as mechanisms for AC [23]. In our patients, 3 of them were diagnosed in an average of 10 to 15 days. All the cases had a good prognosis after cholecystectomy.

Regarding risk factors, we found that diabetes, $\mathrm{CRF}$, smoking, peripheral vascular disease, mostly are seen in GIC patients. Perioperative and postoperative data we found that, long bypass time, usage of IABP, blood transfusion, high lactates level, acute renal failure with hemofiltration, low cardiac output syndrome, are risk factors for GIC.
This is the first study made in Albania for GIC after open heart surgery. We found that our data were the same with the other studies found in literature. When GIC occurs, particularly ischemic intestinal ischemia, the mortality is very high. In a cases of: low cardiac output syndrome, acute renal failure, high quantity of blood transfusion, in cerebrovascular and diabetic patients we should be alert for GIC. Early diagnosis, more chance to survive.

\section{References}

1. Rodriguez F, Nguyen TC, Galanko JA, et al. Gastrointestinal complications after coronary artery bypass grafting: a national study of morbidity and mortality predictors. J Am Coll Surg. 2007; 205:741-7.

2. Andersson B, Nilsson J, Brandt J, et al. Gastrointestinal complications after cardiac surgery. Br J Surg. 2005; 92:326-33.

3. Geissler HJ, Fischer UM, Grunert S, et al. Incidence and outcome of gastrointestinal complications after cardiopulmonary bypass. Interact Cardiovasc Thorac Surg. 2006;5:23942.

4. McSweeney ME, Garwood S, Levin J, et al. Adverse gastrointestinal complications after cardiopulmonary bypass: can outcome be predicted from preoperative risk factors? Anesth Analg. 2004;98:1610-7.

5. Yilmaz AT, Arslan M, Demirkilç U, et al. Gastrointestinal complications after cardiac surgery. Eur J Cardiothorac Surg. 1996;10:7637.

\section{Conclusion}


6. Simic O, Strathausen S, Geidel S, et al. Abdominal complications following cardiac surgery. Acta Med Croatica. 1997;51:191-6.

7. Hashemzadeh K, Hashemzadeh S. Predictors and outcome of gastrointestinal complications after cardiac surgery. Minerva Chir. 2012;67:327-35.

8. Gonzalez OA, Orozco MA, Barrera ZL, et al. Abdominal complications after cardiopulmonary procedures. Rev Gastroenterol Mex 1999; 64: 61-9.

9. Hessel EA. Abdominal organ injury after cardiac surgery. Semin Cardiothorac Vasc Anesth. 2004;8:243-63.

10. Takala J. Determinants of splanchnic blood flow. Br J Anaesth. 1996;77:50-8.

11. Ackland G, Grocott MP, Mythen MG. Understanding gastrointestinal perfusion in critical care: So near, and yet so far. Crit Care. 2000;4:269-81.

12. Sever K, Ozbek C, Goktas B, et al. Gastrointestinal complications after open heart surgery: Incidence and determinants of risk factors. Angiology. 2014;65:425-9

13. Emmiler M, Yaveri A, Kocogulari CU, et al. A. Gastrointestinal ischemia related mortality in patients undergoing off- or onpump coronary artery bypass grafting. Heart Surg Forum 2009 Apr; 12(2):E79-8

14. Croome KP, Kiaii B, Fox S, et al. Comparison of gastrointestinal complications in on-pump versus off-pump coronary bypass grafting. Can J Surg. 2009;52:125-8.

15. Poirier B, Baillot R, Bauset R, et al. Abdominal complications associated with cardiac surgery. Review of a contemporary surgical experience and of a series done without extracorporeal circulation. Can J Surg. 2003;46:176-82

16. Bolcal C, Iyem $H$, Sargin $M$, et al. Gastrointestinal complications after cardiopulmonary bypass: Sixteen years of experience. Can J Gastroenterol. 2005;19:613-7. 17. Filsoufi F, Rahmanian PB, Castillo JG, et al. Predictors and outcome of gastrointestinal complications in patients undergoing cardiac surgery. Ann Surg. 2007;246:323-9

18. Zacharias A, Schwann TA, Parenteau GL, et al. Predictors of gastrointestinal complications in cardiac surgery. Tex Heart Inst J. 2000;27:93-

19. Kazui T, Yamasaki M, Abe K, et al. Nonobstructive mesenteric ischemia: a potentially lethal complication after cardiovascular surgery: report of two cases. Ann Thorac Cardiovasc Surg. 2012;18:56-60.

20. Schoots IG, Koffeman GI, Legemate DA, et al. Systematic review of survival after acute mesenteric ischaemia according to disease aetiology. Br J Surg. 2004;91:17-27

21. Raman JS, Kochi K, Morimatsu H, et al. Severe ischemic early liver injury after cardiac surgery. Ann Thorac Surg. 2002;74:1601-6.

22. Seeto RK, Fenn B, Rockey DC. Ischemic hepatitis: Clinical presentation and pathogenesis. Am J Med. 2000;1:109-13.

23. Sakurai $\mathrm{T}$, Ichimiya $\mathrm{H}$, Miyazaki $\mathrm{H}$, et al. Profiling of eicosanoids in inflamed gall bladder wall by gas chromatography with selected-ion monitoring. J Chromatogr. 1991;15:571 